\title{
Effect of HIV infection on the acute antibody response to malaria antigens in children: an observational study
}

\author{
Daniel KM Muema', Francis M Ndungu', Samson M Kinyanjui ${ }^{1,2}$, James A Berkley ${ }^{1,2^{*}}$
}

\begin{abstract}
Background: In sub-Saharan Africa, the distributions of malaria and HIV widely overlap. Among pregnant and nonpregnant adults, HIV affects susceptibility to malaria, its clinical course and impairs antibody responses to malaria antigens. However, the relationship between the two diseases in childhood, when most deaths from malaria occur, is less clear. It was previously reported that HIV is associated with admission to hospital in rural Kenya with severe malaria among children, except in infancy. HIV-infected children with severe malaria were older, had higher parasite density and increased mortality, raising a hypothesis that HIV interferes with naturally acquired immunity to malaria, hence with little effect at younger ages (a shorter history of exposure). To test this hypothesis, levels of anti-merozoite and schizont extract antibodies were compared between HIV-infected and uninfected children who participated in the original study.
\end{abstract}

Methods: IgG responses to malaria antigens that are potential targets for immunity to malaria (AMA1, MSP2, MSP3 and schizont extract) were compared between $115 \mathrm{HIV}$-infected and 115 age-matched, HIV-uninfected children who presented with severe malaria. The children were classified as high and low responders for each antigen and assigned antibody-response breadth scores according to the number of antigens to which they were responsive. A predictive logistic regression model was used to test if HIV was an effect modifier on the age-related acquisition of antibody responses, with age as a continuous variable.

Results: Point estimates of the responses to all antigens were lower amongst HIV-infected children, but this was only statistically significant for AMA1 $(P=0.028)$. HIV-infected children were less likely to be high responders to AMA1 [OR $0.44(95 \% \mathrm{Cl}, 0.2-0.90) \mathrm{P}=0.024]$. HIV was associated with a reduced breadth of responses to individual merozoite antigens $(P=0.02)$. HIV strongly modified the acquisition of antibodies against schizont extract with increasing age ( $P<0.0001$ ), but did not modify the rate of age-related acquisition of responses to individual merozoite antigens.

Conclusions: In children with severe malaria, HIV infection is associated with a lower magnitude and narrower breadth of IgG responses to merozoite antigens and stunting of age-related acquisition of the IgG antibody response to schizont extract.

\section{Background}

HIV and malaria are major causes of morbidity and mortality in sub-Saharan Africa [1]. Within the region, there is widespread overlap in the distribution of the two diseases [2]. Thus, any interaction between the two diseases may have potentially important public health implications.

\footnotetext{
* Correspondence: jberkley@kilifi.kemri-wellcome.org

${ }^{1}$ Centre for Geographic Medicine Research (Coast), Kenya Medical Research Institute, P.O. Box 230, Kilifi, 80108, Kenya

Full list of author information is available at the end of the article
}

There is evidence that HIV infection influences susceptibility to, and the clinical course of malaria. Studies in non-pregnant [3-7] and pregnant adults [8-10] suggest that HIV infection is associated with more frequent episodes of clinical malaria and higher parasite density. However, reports of the effects of HIV on malaria in childhood, when most malaria deaths occur, have been inconsistent.

Naturally acquired immunity to malaria is dependent on exposure. Thus, in malaria endemic areas, immunity to severe disease, mild disease and parasitaemia 
normally increases with age $[11,12]$. A recent report from Kilifi, Kenya suggested that HIV infection is associated with hospital admission for severe malaria among children [13]. Importantly, those infected with HIV were older (median age, 38 months; IQR, 26-63 months) than those without HIV infection (median age, 19 months; IQR, 10-35 months; P < 0.001). HIV-infected children had higher peripheral parasite density when corrected for age. Despite the overall strong association between HIV infection and severe malaria, there was no relationship between HIV and severe malaria in infancy [13]. This raised the hypothesis that HIV might stunt the age-related acquisition of natural immunity to malaria, thus having little effect among the youngest children who have not yet acquired natural immunity to malaria.

Since both the breadth and magnitude of IgG antibody responses to multiple Plasmodium falciparum merozoite antigens have been associated with immunity to clinical malaria [14], this study was conducted to investigate the effects of HIV infection on the antibody response to three merozoite antigens that are potential targets for immunity to malaria: apical merozoite antigen 1 (AMA1), merozoite surface protein 2 (MSP2) and merozoite surface protein 3 (MSP3); and whole parasite schizont extract.

\section{Methods}

\section{Location and study population}

Kilifi District Hospital, Kenya, serves approximately 240,000 people in a rural, coastal area where malaria is endemic $(<1$ to 120 mosquito bites are infective for P. falciparum each year) [15]. This nested study was conducted using plasma samples collected during a prospective study undertaken between 1998 and 2002 [13]. The prevalence of HIV infection was $1.7 \%$ among children sampled in the community during the study period, and $9.8 \%$ among women attending the hospital antenatal clinic in 2000 [13]. At the time of the study there were no specific HIV care services and consequently no use of anti-retroviral drugs or co-trimoxazole prophylaxis. This 'natural history' study would not now be possible, because of the current widespread use of these drugs. Approval for the study was given by the Kenyan National Ethical Review Committee (SSC No. 502 and SCC No. 485) and individual written informed consent was obtained.

\section{Clinical data collection}

Trained research clinicians provided care and collected standardized clinical and laboratory data on all paediatric admissions. Clinical features of severe malaria were defined as either a history of febrile illness or an axillary temperature $\geq 37.5^{\circ} \mathrm{C}$ on admission, plus one or more of the following signs: impaired consciousness (the inability to localize a painful stimulus if aged $>8$ months, or not having directed eye movements if age $\leq 8$ months), deep breathing (Kussmaul's respiration) or severe anaemia (haemoglobin $<5 \mathrm{~g} / \mathrm{dl}$ ) [13]. Children received supportive care and anti-malarial treatment according to national guidelines and WHO recommendations.

Malaria diagnosis was performed by examining Giemsa-stained thick and thin blood-smears at x1,000 magnification. A full blood count was performed using an MD2 automated counter (Beckman/Coulter, UK). Peripheral parasite densities were calculated from each child's actual red and white cell counts. HIV testing was done retrospectively by enzyme-linked immunosorbent assay after delinking the samples from their identity data; true infection was confirmed by polymerase chain reaction for children aged $<18$ months (Ampliclor; Roche). HIV infection was present in 133 (12\%) of the 1,071 parasitaemic children with signs of severe malaria[13].

\section{Recombinant antigens}

The recombinant MSP2 $\mathrm{CH} 150 / 9$ was expressed in Escherichia coli [16]. MSP3 (full length) was expressed in Escherichia coli [17]. Recombinant AMA1 (1:1 mixture of FVO and 3d7) was expressed in Pichia pastoris [18].

\section{Antibody assays}

The study was conducted using stored plasma samples taken at the time of admission with a diagnosis of severe malaria from 115 HIV-infected children and 115 samples randomly drawn from the larger set of HIV-uninfected children matched on age and season (wet/dry) of admission to eliminate their potential confounding effects.

Enzyme-linked immunosorbent assays (ELISAs) on antibodies against parasite schizont extract and recombinant antigens AMA1, MSP2 and MSP3 were performed as previously described [14]. Briefly, individual wells of microtitre plates (Nunc) were coated with $50 \mathrm{ng}$ of antigen in $100 \mu \mathrm{l}$ of carbonate coating buffer $(15 \mathrm{mM}$ $\mathrm{Na} 2 \mathrm{CO} 3,35 \mathrm{mM} \mathrm{NaHCO} 3, \mathrm{pH}$ 9.3). Alternatively, microtitre plates were coated with $P$. falciparum schizont extract (the A4 strain) in phosphate-buffered saline (PBS) according to the method of Ndungu et al [19]. Plates were incubated overnight at $4{ }^{\circ} \mathrm{C}$ before washing three times in PBS-Tween (PBS-0.05\% Tween 20) and subsequently blocking for five hours at room temperature with $1 \%$ skimmed milk in PBS-Tween. Following this, plates were washed four times and thereafter incubated overnight at $4^{\circ} \mathrm{C}$ with $100 \mu \mathrm{l}$ of test serum $(1 / 500$ dilution in blocking buffer). Plates were then washed four times and then incubated for one hour at room temperature with $100 \mu \mathrm{l}$ of alkaline phosphatase conjugated goat antihuman IgG (Sigma) at 1/500 in blocking buffer. They were then washed four times and 
subsequently incubated for 20 minutes at room temperature with $50 \mu \mathrm{l}$ of diluted p-nitrophenyl phosphate (Sigma) for color development. The reaction was stopped using $50 \mu \mathrm{l}$ of $3 \mathrm{M} \mathrm{NaOH}$. Optical densities were measured at 405/570 nanometers.

A single adult hyper-immune serum, with an assigned IgG antibody concentration in Arbitrary Units (AU), was serially diluted and included in each plate. It was later used to convert the optical density (OD) readings of the samples into relative concentrations in AU, thereby eliminating the effect of inter-plate and interday variation.

\section{Statistical analysis}

The data were analysed with STATA version 11.0 (Stata Corporation, TX, USA). P values $<0.05$ were considered as significant. The Chi squared test was used to compare proportions. As antibody levels were skewed, the Wilcoxon signed-ranks test for matched pairs was used to compare antibody levels (AU) between children with and without HIV infection. Each child was categorized as a high or low responder to each antigen depending on whether their antibody levels were above or below the overall median. Conditional logistic regression, adjusted for age, season, parasite density, haemoglobin and residence in the Northern or Southern part of the district (the two areas have different malaria transmission intensities[20]) was used to determine the odds of a child being a high responder to each antigen. Breadth of merozoite responses was assessed by assigning the children a score on the basis of the number of antigens to which they were high responders i.e. zero to three (response to schizont extract was not included in the score). The Chi squared test for trend was used to test the relationship between breadth of response and HIV status.

To test if HIV infection was acting as an effect modifier on the age-related acquisition of antibody response, a predictive logistic regression model was used with the probability of being a high responder as the dependent variable and age (continuous) and HIV status as independent variables according to the method of Garrett [21] and adjusted for season, parasite density, haemoglobin and residence in the Northern or Southern area. This model estimated the probability of a child being a high responder as age increased, stratified by HIV status. The $\mathrm{P}$ value of the likelihood ratio test (LRT) for the interaction of age*HIV status is reported.

\section{Results}

\section{Characteristics of the study population}

The median age of the HIV infected children included in this analysis was 37 months (interquartile range (IQR) of 25 to 59 months) and that of the age-matched HIV uninfected children was 37 months (IQR 25 to
59 months). Two HIV-uninfected and four HIV-infected children had concurrent bacteraemia. Eight HIV-uninfected and fourteen HIV-infected children died. There were no significant differences between the two groups with regard to nutritional status and the three main clinical features of severe malaria (i.e. anaemia, unconsciousness and deep breathing) (Table 1).

\section{Antibodies to merozoite antigens and HIV infection status} The point estimates of levels of antibodies to all the antigens tested were lower among HIV-infected children. This was statistically significant for antibodies against AMA1 $(\mathrm{P}=0.028)$ but not for those against MSP2 $(\mathrm{P}=0.90)$, MSP3 $(\mathrm{P}=0.09)$ or schizont extract $(\mathrm{P}=0.10)$ (Figure 1). HIV infected children were less likely to be high responders to AMA1 [OR 0.44 (95\%CI, $0.2-0.90) \mathrm{P}=0.024]$. There was no significant difference with regard to MSP2 [OR $0.68(95 \% \mathrm{CI}, 0.31-1.46) \mathrm{P}=$ 0.32], MSP3 [OR 0.74 (95\% CI, 0.34-1.59) $\mathrm{P}=0.44$ ] or schizont extract [OR $0.67(95 \%$ CI $0.36-1.57) \mathrm{P}=$ 0.36]. HIV infection interfered with the breadth of antibody response to merozoite antigens. The proportion of HIV infected children decreased as breadth score increased (Chi squared test for trend $\mathrm{P}=0.02$, Figure 2).

HIV infection was a strong effect modifier on the agerelated acquisition of antibody response against the schizont extract (LRT $=18.73, \mathrm{P}<0.0001)$, with no increase in the probability of being a high responder against schizont extract with increasing age among HIV-infected children (Figure 3). However, there was no evidence for effect modification by HIV on the age-related acquisition of responses to the individual merozoite antigens: AMA1 $(\mathrm{LRT}=0.67, \mathrm{P}=0.41), \mathrm{MSP} 2(\mathrm{LRT}=0.43, \mathrm{P}=0.51)$ and MSP3 (LRT $=0.26, P=0.61$ ). Thus, although the point estimates of the probabilities of being a high responder

\section{Table 1 Population characteristics}

\begin{tabular}{|c|c|c|c|}
\hline & $\underline{\text { HIV-uninfected }}$ & $\underline{\text { HIV-infected }}$ & $\underline{P \text { value }}$ \\
\hline N & 115 & 115 & \\
\hline $\begin{array}{l}\text { Age in months median } \\
\text { (Interquartile range)* }\end{array}$ & $\begin{array}{c}37 \\
(25-59)\end{array}$ & $\begin{array}{c}37 \\
(25-59)\end{array}$ & 1.00 \\
\hline $\begin{array}{l}\text { Parasite density median } \\
\text { (Interquartile range) }\end{array}$ & $\begin{array}{c}26441 \\
(2860-124800)\end{array}$ & $\begin{array}{c}40413 \\
(3039-148780)\end{array}$ & 0.90 \\
\hline Severely anaemic ${ }^{1}$ & 68 & 68 & 0.87 \\
\hline Unconscious $^{2}$ & 39 & 45 & 0.47 \\
\hline Bacteraemia ${ }^{3}$ & 2 & 4 & 0.42 \\
\hline Deep acidotic breathing & 27 & 24 & 0.58 \\
\hline Malnutrition ${ }^{4}$ & 30 & 34 & 0.61 \\
\hline Death & 8 & 14 & 0.19 \\
\hline
\end{tabular}

${ }^{*}$ Groups were matched on age.

${ }^{1}$ haemoglobin $<5 \mathrm{~g} / \mathrm{dl}$.

${ }^{2}$ inability to localize a painful stimulus for children aged 18 months or lack of directed eye movements for infants aged $<8$ months.

${ }^{3}$ positive aerobic blood culture for pathogenic bacteria.

${ }^{4}$ severe underweight (weight-for-age z score, <3) or having kwashiorkor. 


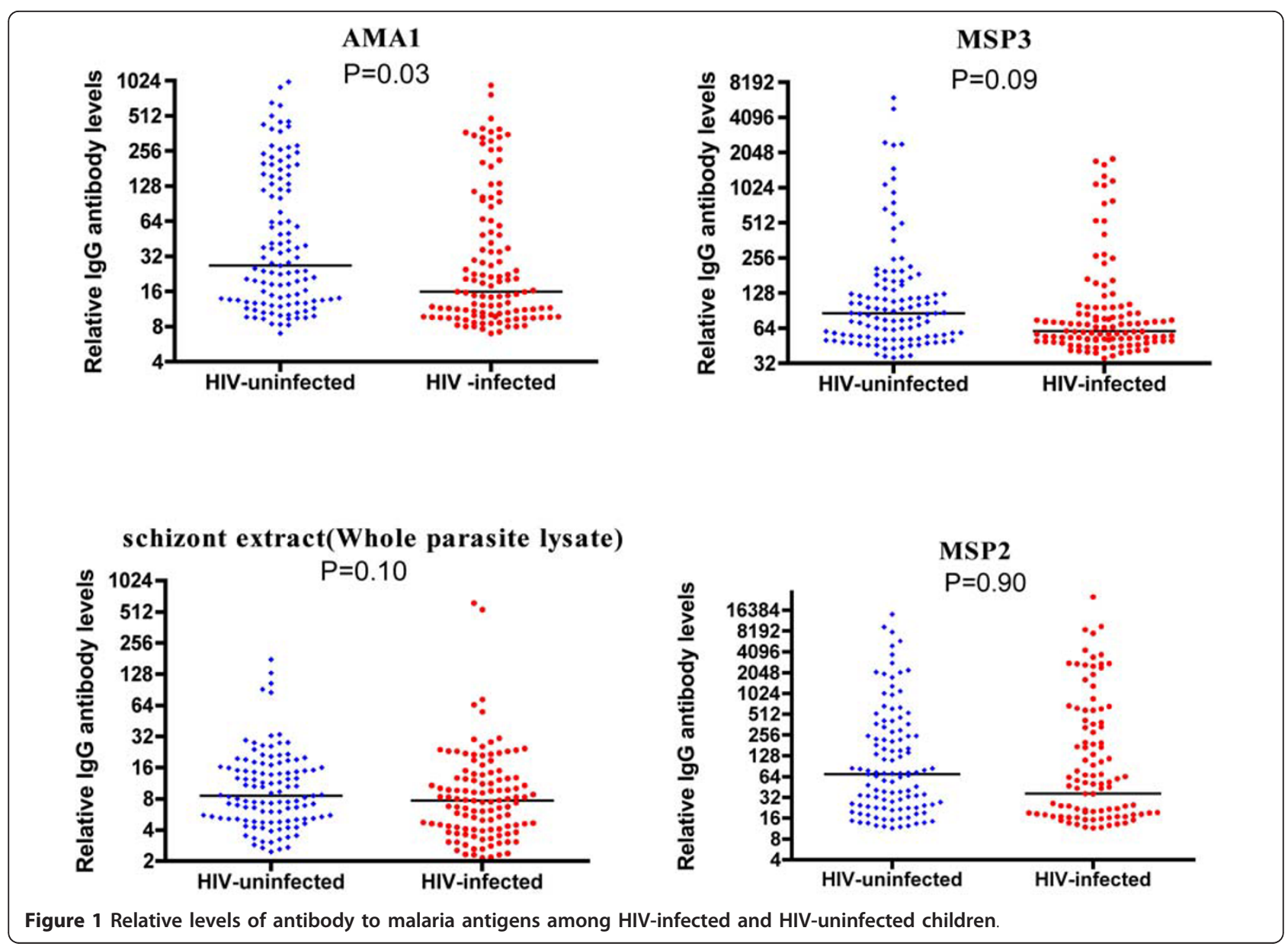

were consistently lower among the HIV-infected children, estimates of the probability of being a high responder for these individual merozoite antigens increased with age, regardless of the HIV status (Figure 3).

\section{Discussion}

This study suggests that HIV-infected children have impaired ability to respond to multiple malaria antigens

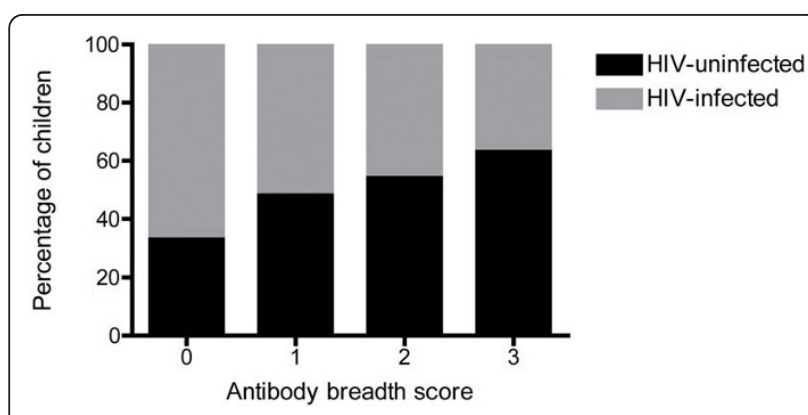

Figure 2 Breadth of response scores for three merozoite antigens among HIV-infected and HIV-uninfected children. Chi squared test for trend $\mathrm{P}=0.02$. and HIV modifies the age-related acquisition of antibodies to $P$. falciparum whole parasite schizont extract. Thus, HIV infection impairs both the magnitude and breadth of antibody response. Since antibodies are important in immunity to severe malaria [22], these results are compatible with the previous epidemiological observations which suggested that HIV stunts the age-related acquisition of immunity to severe malaria (increased age, parasite density and case fatality) [13]. The inconsistent findings of studies of the association between HIV and malaria in children may therefore reflect the fact that the observed effect of HIV on malaria is likely to depend on both age and transmission intensity.

The response to schizont extract is a reflection of the total response to the many individual antigens in the malaria parasite. As such, the observed effect modification by HIV on the age-related acquisition of response is likely to reflect the cumulative effect modification on the acquisition of responses to many malaria antigens, which might not be observed if the individual responses are studied separately.

The stunting of age-related acquisition of antibodies to malaria antigens by HIV observed in this study 

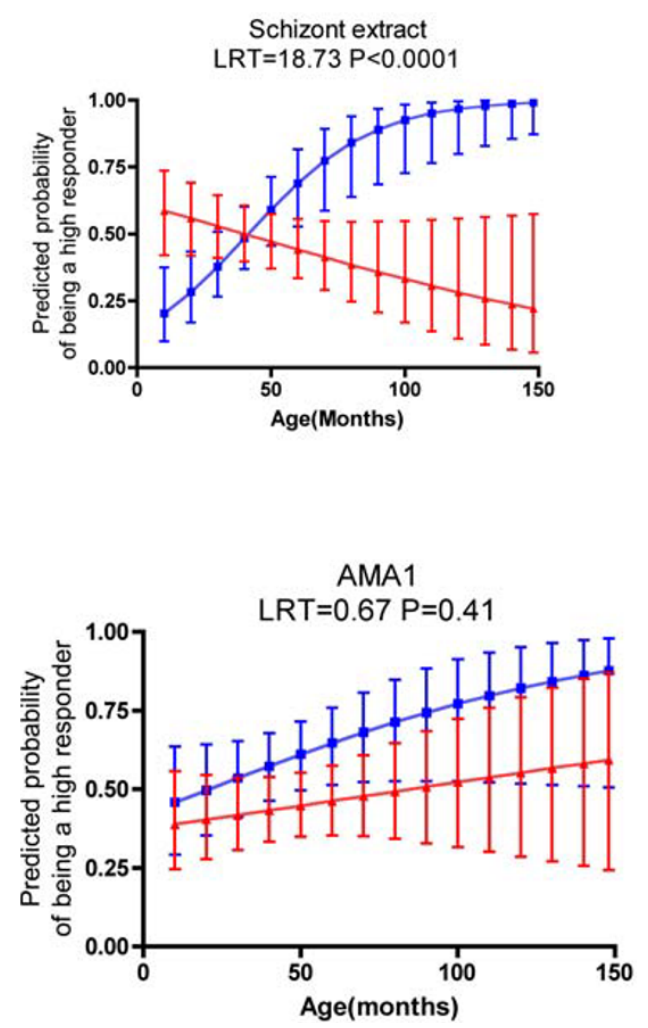

MSP2

LRT $=0.43 P=0.51$

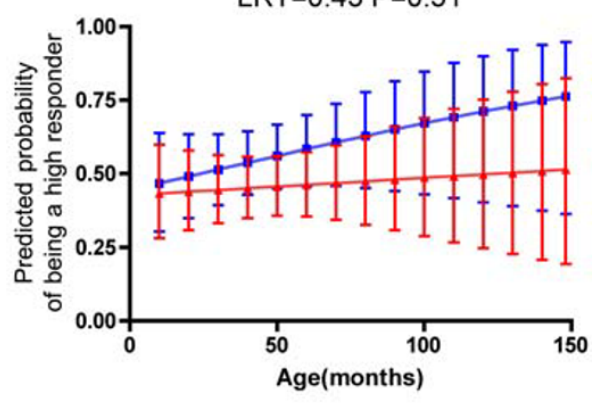

MSP3

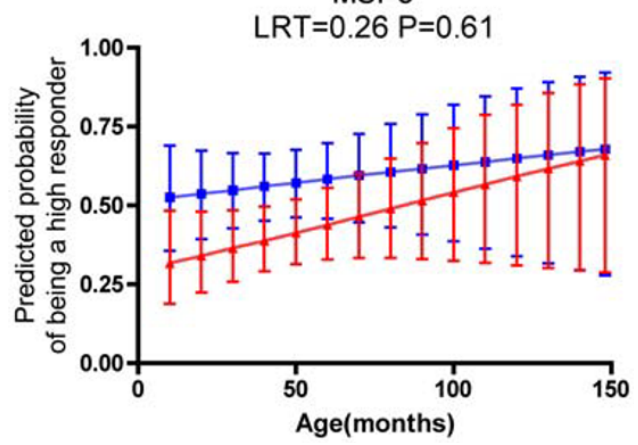

Figure 3 Probability of being a high responder against the various antigens with increasing age. Blue represents HIV-uninfected children while red represents HIV-infected children. Error bars indicate the $95 \%$ confidence intervals. LRT refers to the likelihood ratio test for the interaction of age*HIV status in the logistic regression model.

parallels the impaired parity-dependent acquisition of antibodies against the variant surface antigens associated with placental malaria parasites reported among Malawian HIV-infected pregnant women [23]. Consistent with the results of this study the HIV-infected women also had reduced antibodies against AMA1. Similarly, among non-pregnant Zambian adults, HIV impaired the antibody response to AMA1 but spared antibody responses to MSP2 [24].

Previous studies among adults have reported that the risk of malaria infection and severe disease rises with increasing derangement of the immune system due to HIV and is highest among individuals with the lowest CD4 cells counts [3,7,25-27], suggesting that the interaction between HIV and malaria is immunological. However, the mechanism by which HIV affects antibody responses to malaria is unclear. In more advanced stages of HIV infection, malaria responses are probably stunted along with the global stunting of all immune responses. One possible specific mechanism by which HIV could stunt IgG responses to parasites, including malaria, is through the HIV Nef, an HIV viral protein, which accumulates in B cells and prevents class switching of HIV and non-HIV responses $[28,29]$. However, observations in this study and the other studies cited above suggest that in the earlier stages of infection, HIV also influences specific malaria responses.

It can be argued that, in one sense, protection against severe malaria had failed in all of these children since they all had severe malaria. However, responses differed between HIV-infected and uninfected children, suggesting true differences in rapid antibody responses during this severe episode. Furthermore, in the original study, the HIV infected children had higher parasitaemia and were more likely to die, suggesting that they were more immunologically deficient in terms of their ability to control the malaria episode.

The study was limited to three malaria merozoite antigens and the whole parasite lysate. The effect of HIV on the variant surface antigens (VSAs) and the remaining thousands of malaria antigens, the majority of which are yet to be expressed and purified into recombinant proteins, remains unexplored. Additionally, the sample size was restricted to the number of available HIV-infected plasma samples from the parent study. There were no 
data on CD4 counts or HIV viral loads from the children in this study.

\section{Conclusions}

In children with severe malaria, HIV infection is associated with a lower magnitude and narrower breadth of IgG responses to merozoite antigens and stunting of age-related acquisition of antibody responses to schizont extract. Further research should investigate fractionated schizont extract to identify the most significant components; the effect of HIV on avidity maturation; functionality of the antibodies; and the ability of HIV-infected children to mount effective responses to current and putative malaria vaccines.

\section{Acknowledgements}

We thank the patients and staff of Kilifi District Hospital for participation in this study. We are grateful to Professor Kevin Marsh and Dr Faith Osier for helpful discussions and to Jedida Mwacharo for assistance in the laboratory. This paper is published with the approval of the Director of KEMRI. This work was supported by the Kenya Medical Research Institute and the Wellcome Trust, UK. [Grant numbers 053439 and 084538]

\section{Author details}

${ }^{1}$ Centre for Geographic Medicine Research (Coast), Kenya Medical Research Institute, P.O. Box 230, Kilifi, 80108, Kenya. ${ }^{2}$ Centre for Clinical Vaccinology \& Tropical Medicine, University of Oxford, Oxford, UK.

\section{Authors' contributions}

$J A B$ and SMK conceived the study. JAB undertook patient care and sample collection. Laboratory methods were designed by DKMM, FMN and SMK and undertaken by DKMM and FMN. Analysis was conducted by DKMM and JAB. The manuscript was drafted by DKMM and critically reviewed and edited by all authors.

\section{Conflict of interests}

The authors declare that they have no competing interests.

Received: 2 January 2011 Accepted: 5 March 2011

Published: 5 March 2011

\section{References}

1. Lopez AD, Mathers CD, Ezzati M, Jamison DT, Murray CJ: Global and regional burden of disease and risk factors, 2001: systematic analysis of population health data. Lancet 2006, 367:1747-1757.

2. "Malaria and HIV interactions and their implications for public health policy "(report of a technical consultation, Geneva, Switzerland, 2004). World Health Organization; [http://www.who.int/hiv/pub/prev_care/ malariahiv.pdf], Accessed 23 October 2010.

3. Whitworth J, Morgan D, Quigley M, Smith A, Mayanja B, Eotu H, Omoding N, Okongo M, Malamba S, Ojwiya A: Effect of HIV-1 and increasing immunosuppression on malaria parasitaemia and clinical episodes in adults in rural Uganda: a cohort study. Lancet 2000, 356:1051-1056.

4. Francesconi P, Fabiani M, Dente MG, Lukwiya M, Okwey R, Ouma J, Ochakachon R, Cian F, Declich S: HIV, malaria parasites, and acute febrile episodes in Ugandan adults: a case-control study. AIDS 2001, 15:2445-2450.

5. Chirenda J, Siziya S, Tshimanga M: Association of HIV infection with the development of severe and complicated malaria cases at a rural hospital in Zimbabwe. Cent Afr J Med 2000, 46:5-9.

6. Patnaik P, Jere CS, Miller WC, Hoffman IF, Wirima J, Pendame R, Meshnick SR, Taylor TE, Molyneux ME, Kublin JG: Effects of HIV-1 serostatus, HIV-1 RNA concentration, and CD4 cell count on the incidence of malaria infection in a cohort of adults in rural Malawi. $J$ Infect Dis 2005, 192:984-991.

7. Cohen C, Karstaedt A, Frean J, Thomas J, Govender N, Prentice E, Dini L, Galpin J, Crewe-Brown H: Increased prevalence of severe malaria in HIVinfected adults in South Africa. Clin Infect Dis 2005, 41:1631-1637.

8. Steketee RW, Wirima JJ, Bloland PB, Chilima B, Mermin JH, Chitsulo L, Breman JG: Impairment of a pregnant woman's acquired ability to limit Plasmodium falciparum by infection with human immunodeficiency virus type-1. Am J Trop Med Hyg 1996, 55:42-49.

9. Verhoeff FH, Brabin BJ, Hart CA, Chimsuku L, Kazembe P, Broadhead RL: Increased prevalence of malaria in HIV-infected pregnant women and its implications for malaria control. Trop Med Int Health 1999, 4:5-12.

10. Ladner J, Leroy V, Simonon A, Karita E, Bogaerts J, De Clerca A, Van De Perre P, Dabis F: HIV infection, malaria, and pregnancy: a prospective cohort study in Kigali, Rwanda. Am J Trop Med Hyg 2002, 66:56-60.

11. Weiss GE, Traore B, Kayentao K, Ongoiba A, Doumbo S, Doumtabe D, Kone Y, Dia S, Guindo A, Traore A, Huang CY, Miura K, Mircetic M, Li S, Baughman A, Narum DL, Miller LH, Doumbo OK, Pierce SK, Crompton PD: The Plasmodium falciparum-specific human memory B cell compartment expands gradually with repeated malaria infections. PLoS Pathog 6: e1000912.

12. Marsh $\mathrm{K}$, Kinyanjui S: Immune effector mechanisms in malaria. Parasite Immunol 2006, 28:51-60.

13. Berkley JA, Bejon P, Mwangi T, Gwer S, Maitland K, Williams TN, Mohammed S, Osier F, Kinyanjui S, Fegan G, Lowe BS, English M, Peshu N Marsh K, Newton CR: HIV infection, malnutrition, and invasive bacterial infection among children with severe malaria. Clin Infect Dis 2009, 49:336-343.

14. Osier FH, Fegan G, Polley SD, Murungi L, Verra F, Tetteh KK, Lowe B, Mwangi T, Bull PC, Thomas AW, Cavanagh DR, McBride JS, Lanar DE, Mackinnon MJ, Conway DJ, Marsh K: Breadth and magnitude of antibody responses to multiple Plasmodium falciparum merozoite antigens are associated with protection from clinical malaria. Infect Immun 2008, 76:2240-2248.

15. Keating J, Mbogo CM, Mwangangi J, Nzovu JG, Gu V, Regens JL, Yan G, Githure JI, Beier JC: Anopheles gambiae s.I. and Anopheles funestus mosquito distributions at 30 villages along the Kenyan coast. J Med Entomol 2005, 42:241-246.

16. Taylor RR, Smith DB, Robinson VJ, McBride JS, Riley EM: Human antibody response to Plasmodium falciparum merozoite surface protein 2 is serogroup specific and predominantly of the immunoglobulin G3 subclass. Infect Immun 1995, 63:4382-4388.

17. Tsai CW, Duggan PF, Jin AJ, Macdonald NJ, Kotova S, Lebowitz J, Hurt DE, Shimp RL Jr, Lambert L, Miller LH, Long CA, Saul A, Narum DL: Characterization of a protective Escherichia coli-expressed Plasmodium falciparum merozoite surface protein 3 indicates a non-linear, multidomain structure. Mol Biochem Parasitol 2009, 164:45-56.

18. Traore B, Kone Y, Doumbo S, Doumtabe D, Traore A, Crompton PD, Mircetic M, Huang CY, Kayentao K, Dicko A, Sagara I, Ellis RD, Miura K, Guindo A, Miller LH, Doumbo OK, Pierce SK: The TLR9 agonist CpG fails to enhance the acquisition of Plasmodium falciparum-specific memory B cells in semi-immune adults in Mali. Vaccine 2009, 27:7299-7303

19. Ndungu FM, Bull PC, Ross A, Lowe BS, Kabiru E, Marsh K: Naturally acquired immunoglobulin ( $\mathrm{Ig}) \mathrm{G}$ subclass antibodies to crude asexual Plasmodium falciparum lysates: evidence for association with protection for IgG1 and disease for IgG2. Parasite Immunol 2002, 24:77-82.

20. Snow RW, Omumbo JA, Lowe B, Molyneux CS, Obiero JO, Palmer A, Weber MW, Pinder M, Nahlen B, Obonyo C, Newbold C, Gupta S, Marsh K: Relation between severe malaria morbidity in children and level of Plasmodium falciparum transmission in Africa. Lancet 1997, 349:1650-1654.

21. Garrett JM: PREDXCON: Stata module to calculate predicted means, medians, or proportions for a continuous $\times$ variable. Statistical Software Components, Boston College Department of Economics 2005.

22. Cohen $\mathrm{S}, \mathrm{Mc} \mathrm{Gl}$, Carrington S: Gamma-globulin and acquired immunity to human malaria. Nature 1961, 192:733-737.

23. Mount AM, Mwapasa V, Elliott SR, Beeson JG, Tadesse E, Lema VM, Molyneux ME, Meshnick SR, Rogerson SJ: Impairment of humoral immunity to Plasmodium falciparum malaria in pregnancy by HIV infection. Lancet 2004, 363:1860-1867. 
24. Van Geertruyden JP, Van Eijk E, Yosaatmadja F, Kasongo W, Mulenga M, D'Alessandro U, Rogerson S: The relationship of Plasmodium falciparum humeral immunity with HIV-1 immunosuppression and treatment efficacy in Zambia. Malar J 2009, 8:258.

25. French N, Nakiyingi J, Lugada E, Watera C, Whitworth JA, Gilks CF: Increasing rates of malarial fever with deteriorating immune status in HIV-1-infected Ugandan adults. Aids 2001, 15:899-906.

26. Mermin J, Lule JR, Ekwaru JP: Association between malaria and CD4 cell count decline among persons with HIV. J Acquir Immune Defic Syndr 2006, 41:129-130.

27. Laufer MK, van Oosterhout JJ, Thesing PC, Thumba F, Zijlstra EE, Graham SM, Taylor TE, Plowe CV: Impact of HIV-associated immunosuppression on malaria infection and disease in Malawi. J Infect Dis 2006, 193:872-878.

28. Qiao X, He B, Chiu A, Knowles DM, Chadburn A, Cerutti A: Human immunodeficiency virus $1 \mathrm{Nef}$ suppresses CD40-dependent immunoglobulin class switching in bystander B cells. Nat Immunol 2006, 7:302-310

29. Xu W, Santini PA, Sullivan JS, He B, Shan M, Ball SC, Dyer WB, Ketas TJ, Chadburn A, Cohen-Gould L, Knowles DM, Chiu A, Sanders RW, Chen K, Cerutti A: HIV-1 evades virus-specific $\lg G 2$ and IgA responses by targeting systemic and intestinal B cells via long-range intercellular conduits. Nat Immunol 2009, 10:1008-1017.

doi:10.1186/1475-2875-10-55

Cite this article as: Muema et al:: Effect of HIV infection on the acute antibody response to malaria antigens in children: an observational study. Malaria Journal 2011 10:55.

\section{Submit your next manuscript to BioMed Central} and take full advantage of:

- Convenient online submission

- Thorough peer review

- No space constraints or color figure charges

- Immediate publication on acceptance

- Inclusion in PubMed, CAS, Scopus and Google Scholar

- Research which is freely available for redistribution

Submit your manuscript at www.biomedcentral.com/submit
C BioMed Central 